\title{
Spectral Depth Analysis of Sokoto Basin.
}

\author{
Bonde,D. S*.1 Udensi E. E ${ }^{2}$; Rai J. K. \\ ${ }^{I}$ Department of physics, Kebbi State University of Science and Technology, Aliero \\ Department of physics, Federal University Technology, Minna.
}

\begin{abstract}
Spectral depth analysis of Sokoto basin was carried out to determine the the sedimentary thickness in all parts of the basin, The total magnetic field values, obtained by digitizing the contour maps of the basin, was used to produce the composite map of the area. The Sokoto Basin is situated between latitudes $10^{\circ} 30^{\prime \prime} \mathrm{N}$ to $14^{\circ} 00^{\prime \prime} \mathrm{N}$ and longitude $3^{\circ} 30^{\prime \prime} E$ to $7^{\circ} 00^{\prime \prime} E$ with an estimated area of $59,570 \mathrm{~km}^{2}$.Spectral depth analysis was carried out on each aeromagnetic sheet to estimate the depth to basement and infer areas of probable hydrocarbon prospects. The results of the spectral studies indicate an increase in sedimentation northwards, with several depressions on the basement rock. Two prominent magnetization layers of depths varying from 0.04 $\mathrm{km}$ to $0.95 \mathrm{~km}$ and $0.36 \mathrm{~km}$ to $2.88 \mathrm{~km}$ were observed. The areas, where higher sedimentary thicknesses are observed such as sheets No 28(Argungu), sheet no.12 (Isah) and sheet no. 13(Gandi) are the most probable sites for prospect of hydrocarbon accumulation in the basin.

Key words: Geophysical investigation; Composite map; Sedimentary thickness; Anomalies.
\end{abstract}

\section{Introduction}

The earth and its contents have long been of concern to mankind. Man has tried to unravel its complexity and delve into its origin via various geophysical methods. The subsurface has been of particular concern to geoscientists, who seek to investigate it using diverse means, some for the purpose of having knowledge, while others do it for exploration of economic resources such as minerals and hydrocarbons. With the advances in technology and the need to have a clearer picture of the earth subsurface and its contents, the earth scientists have deemed it necessary to utilize the properties associated with earth's interior.

Geophysics involves the application of physical principles and quantitative physical measurements in order to st udy the earth's interior, its atmosphere and terrestrial space. The analysis of these measurements can reveal how the earth interior varies both vertically and laterally, and the interpretation of which can reveal meaningful inf ormation on the geological structures beneath, Dobrin(1976).

By working at different scales, geophysical methods may be applied to a wide range of investigations from studies of the entire Earth to exploration of a localized region of the upper crust for engineering or other purposes (Keareyet al., 2004). A wide range of geophysical methods exist for each of which there is an operative physical property to which the method is sensitive. The type of physical property to which a met hod responds clearly determines its range of application. Thus, for instance, magnetic method is very suitable $f$ or locating buried magnetic ore bodies because of their magnetic susceptibility. Similarly, seismic and electrical methods are suitable for locating water table, because saturated rock may be distinguished from dry rock by its higher seismic velocity and higher electrical conductivity (Keareyet al., 2004).

In exploration for subsurface resources, the geophysical methods are capable of detecting and delineating local features of potential interest. Geophysical methods for detecting discontinuities, faults, joints and other basement structures, include the following: magnetics, seismic, resistivity, electrical, potential field, well logging, gravity, radiometric, thermal etc (Corell andGrauch,1985). Some geophysical methods such as gammaray spectrometry and remote sensing measure surface attributes; others, such as thermal and some electrical methods are limited to detecting relatively shallow subsurface geological features. Geophysical modeling provides generalized and no-unique solution to questions concerning the concerning the geometry of the subsurface geologic structures (Reeves, 2005).

Most economic minerals, oil, gas, and groundwater lie concealed beneath the earth surface, thus hidden from direct view. The presence and magnitude of these resources can only be ascertained by geophysical investigations of the subsurface geologic structures in the area.If the area under investigation has no previous geological information and the primary aim of the study is to search for hydrocarbon deposits; the first question that must be answered, is whether the sedimentary basin is large enough and thick enough to justify any further investigations ( Reynolds, 1990).

Other criteria for assessing a basin for possible hydrocarbon accumulation are as follows:

$>$ Source rock: The presence of a source rock with adequate organic materials of various types determines whether oil or gas will be sourced in the process of hydrocarbon generation.

$>$ Reservoir rock: Reservoir rock ensures that hydrocarbon generated are accommodated in pore spaces that exists between the grains in the subsurface. 
$>$ Seal: seals are normally without pore spaces ensures that hydrocarbon generated in the reservoir rocks are kept in place and prevented from migrating to the surface and subsequent loss.

$>$ Paleotemperatures: Paleotemperatures or ancient Paleotemperatures are responsible for generation of hydrocarbon from organic matter.

$>$ Trap:The trap ensures that oil sealed in place does not migrate and be lost.

In this study, aeromagnetic data of theSokoto Basin is analyzed by techniques of spectral depth analysis in order to estimate the sedimentary thickness in all parts of the basin and suggest areas of likely hydrocarbon accumulation prospects..

\subsection{Data Acquisition}

\section{Materials And Methods}

The study area (Sokoto Sedimentary Basin) is covered by thirty aeromagnetic maps of total field intensity in half -degree sheets. These maps are obtained from the Nigerian Geological Survey Agency (NGSA), now renamed the Nigerian Geological Survey Agency (NGSA)). The Agency carried out an airborne magnetic survey of substantial part of Nigeria between 1974 and 1980. The magnetic information consists of flight lines plotted on a continuous strip chart or tape records. The data were collected at a nominal flight altitude of $152.4 \mathrm{~m}$ along $\mathrm{N}$-S flight lines spaced approximately $2 \mathrm{~km}$ apart. The magnetic data collected were published in the form $1 / 2$ degree aeromagnetic maps on a scale of 1:100,000. The magnetic values were plotted at $10 \mathrm{Nt}$ (nano Tesla) interval. The maps are numbered, and names of places and coordinates (longitude and latitudes) written for easy reference and identification. The actual magnetic values were reduced by 25,000gamma before plotting the contour map. This implies that the value 25,000 gamma is to be added to the contour values so as to obtain the actual magnetic field at a given point. A correction based on the International Geomagnetic Reference Field, (IGRF,) and epoch date January 1, 1974 was included in all the maps.

The visual interpolation method, that is the method of digitizing on Grid Layout was used to obtain the data fro $m$ field intensity aeromagnetic maps covering the study area. The data from each digitized map is recorded in a 19 by 19 coding sheet which contains the longitude, latitude and the name of the town flown and thesheet number.The unified composite dataset for the study area was produced after removing the edge effect. Surfer 8 Geosoft ware was used to import the dataset. The dataset consists of three columns (longitude,latitude and magnetic values). The composite map was produced using Oasis Montaj..

\subsection{Regional-residual Separation}

Magnetic data observed in geophysical surveys comprises of the sum of all magnetic fields produced by all underground sources. The composite map produced using such data, therefore contains two important disturbances, which are different in order of sizes and generally super-imposed. The large features generally show up as trends, which continue smoothly over a considerable distance. These trends are known as regional trends. Super-imposed on the regional field, but frequently camouflaged by these, is the smaller, local disturbances which are secondary in size but primary in importance. These are the residual anomalies. They may provide direct evidence of the existence of the reservoir type structures or mineral ore bodies.

\subsection{Production of Regional and Residual Maps}

The residual magnetic field of the study area was produced by subtracting the regional field from the total magnetic field using the Polynomial fitting method. The computer program Aerosupermap was used to generate the coordinates of the total intensity field data values. This super data file, for all the magnetic values was used for production of composite aeromagnetic map of the study area using Oasis Montaj software version 7.2 A program was used to derive the residual magnetic values by subtracting values of regional field from the total magnetic field values to produce the residual magnetic map and the regional map.

\subsection{Spectral Depth Analysis}

Determination of depths to buried magnetic rocks is among the principal applications of an aeromagnetic data. The depths are commonly computed from measurement made on the widths and slopes of an individual anomaly of the aeromagnetic profiles. The statistical approach has been found to yield good estimates of mean depth to basement underlying a sedimentary basin( Hahnetal., 1976, Udensi,2001). Spector (1968) and Spector and Grant (1970) developed a depth determination method which matches two dimensional power spectral calculated from gridded total magnetic intensity field data with corresponding spectral obtained from a theoretical model. For the purpose of analyzing aeromagnetic data, the ground is assumed to consist of a number of independent ensembles of rectangular, vertical sided parallelepiped, and each is ensemble characterized by a joint frequency distribution for the depth (h) and length( $b$ ) and depth extent $(t)$

In this work, the characteristics of the residual magnetic field are studied using statistical spectral methods. This is done by first transforming the data from space to the frequency domain and then analyzing their frequency 
characteristics. In the general case, the radial spectrum may be conveniently approximated by straight line segments, the slopes of which relate to depths of the possible layers, (Spector and Grant, 1970, and Hahn etal.,1976). The residual total magnetic field intensity values are used to obtain the two dimensional Fourier Transform, from which the spectrum is to be extracted from the residual values $\mathrm{T}(\mathrm{x}, \mathrm{y})$ consisting of $\mathrm{M}$ rows and $\mathrm{N}$ columns in $\mathrm{X}-\mathrm{Y}$. The two dimensional Fourier transforms is obtained as given in equation (3.1) above. The evaluation is done using an algorithm that is a two dimensional extension of the fast Fourier transform (Oppenheim and Schafer, 1975). Next, the frequency intervals are subdivided into sub-intervals, which lie within one unit of frequency range.

The average spectrum of the partial values together constitutes the redial spectrum of the anomalous field (Hahn et al., 1976, Kangkolo, 1996 and Udensi, 2001).

The logarithm of the energy values versus frequency on a linear scale was plotted and the linear segments located; The use of Discrete Fourier Transform introduced the problem of aliasing and the truncation effect (or Gibbs phenomenon). Aliasing was reduced by the digitizing interval used in the study.

Three or two linear segments could be seen from the graphs. The first points on the frequency scale was ignored because the low frequency components in the energy spectrum are generated from the deepest layers whose locations are most likely in errors. each linear segment groups points due to anomalies caused by bodies occurring within a particular depth. If the $\mathrm{z}$ is the mean depth of the layer, the depth factor for this ensemble of anomalies is exp (-2zk). Thus the logarithmic plot of the radial spectrum would give a straight line whose slope is $-2 \mathrm{z}$.

The mean depth of the burial ensemble is thus given as

$$
Z=-\frac{m}{2}
$$

Where $(\mathrm{m})$ is the slope of the best fitting straight line

\section{1}

Equation 2.1 can be applied directly if the frequency unit is in radian per kilometer. If however, the frequency unit is in circle per kilometer, the corresponding relationship can be expressed as

$$
Z=-\frac{m}{4 \pi}
$$

\subsection{Total Magnetic Intensity Map.}

\section{Results}

The total magnetic intensity map (TMI) of the Sokoto sedimentary basin produced from this study using Oasis Montaj version 7.2 is as shown in Figure 1.The TMI map of Sokoto sedimentary basin can be divided into main three sections, though minor depressions exist scattered all over area. The northern part of the Sokoto basin is characterized by low magnetic intensity values represented by dark-green-blue color. Whereas the southern part is dominated by high magnetic intensity values indicated by red color. The two sections are separated by a zone characterized by medium magnetic intensity values area depicted by yellow-orange color. These high magnetic intensity values, which dominate the southern part of the Sedimentary basin are caused probably by near surface igneous rocks of high values of magnetic susceptibilities. The low amplitudes are most likely due to sedimentary rocks and other non-magnetic sources. In general, high magnetic values arise from igneous and crystalline basement rocks. Whereas low magnetic values are usually from sedimentary rocks or altered basement rocks. The sedimentary thickness of theSokoto basin in general, appears to increases from south to north. This collaborates well with earlier findings of 2D Seismic surveys conducted by ELF and Mobil Companies carried out in 1979.

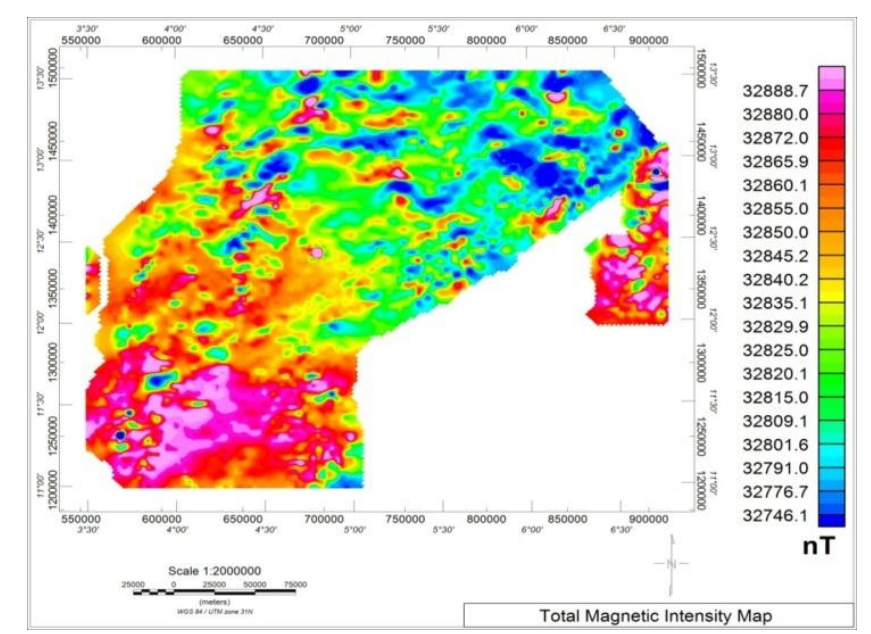

Figure 1Total magnetic intensity map of the study area. 
3.2 Regional Magnetic Intensity Map.

The regional magnetic intensity map of the study area (Figure 2) produced using Oasis Montaj version 7.2 is as shown.

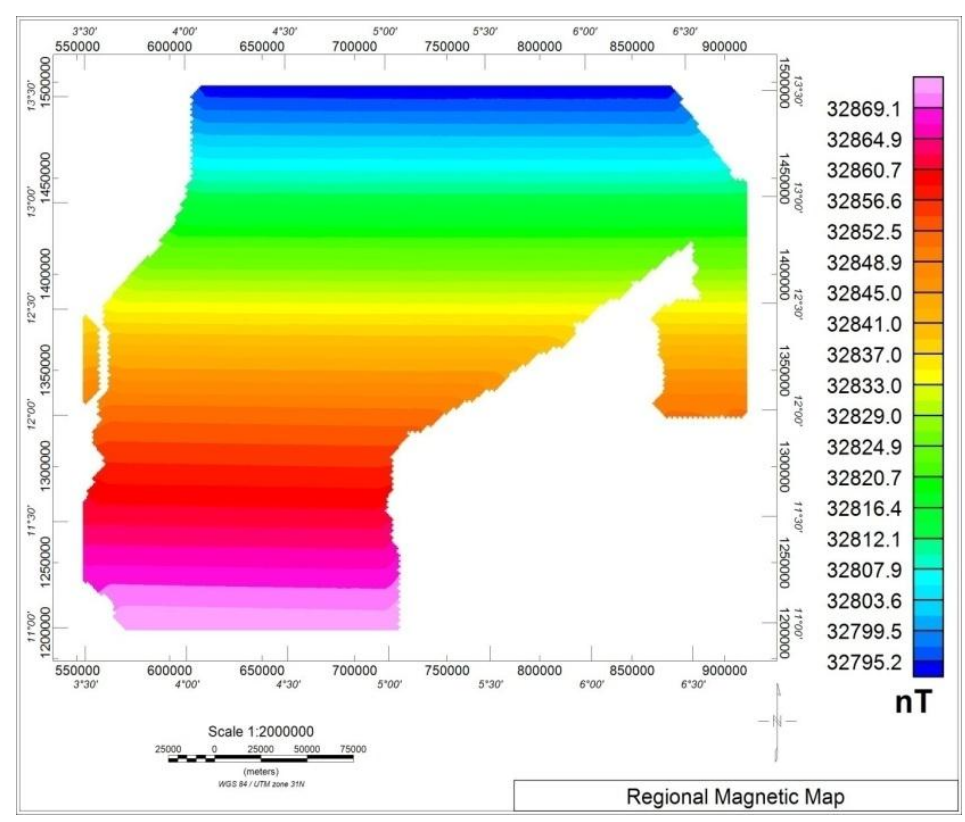

Figure 2 Regional Map of the Study Area

The regional magnetic values ranges from 7830 nano tesla to 7870 nano tesla and the values decreases from south to north indicating there is a fill of sediments more in the northern part of the basin than in the southern part of the study area

\subsection{Residual Magnetic Intensity Map.}

Figure 3 and Figure 4 are the residual magnetic intensity maps of the study area obtained from the total magnetic intensity map produced using Surfer 8 and Oasis Montaj version 7.2 respectively.The magnetic intensity values ranges from -10 nano tesla to 40 nano tesla. Negative magnetic intensity values are more predominant in the northern section of the study area while the southwest has more of positive magnetic intensity values.Northeast -Southwest trends are observed in the north central part of the TMI map.

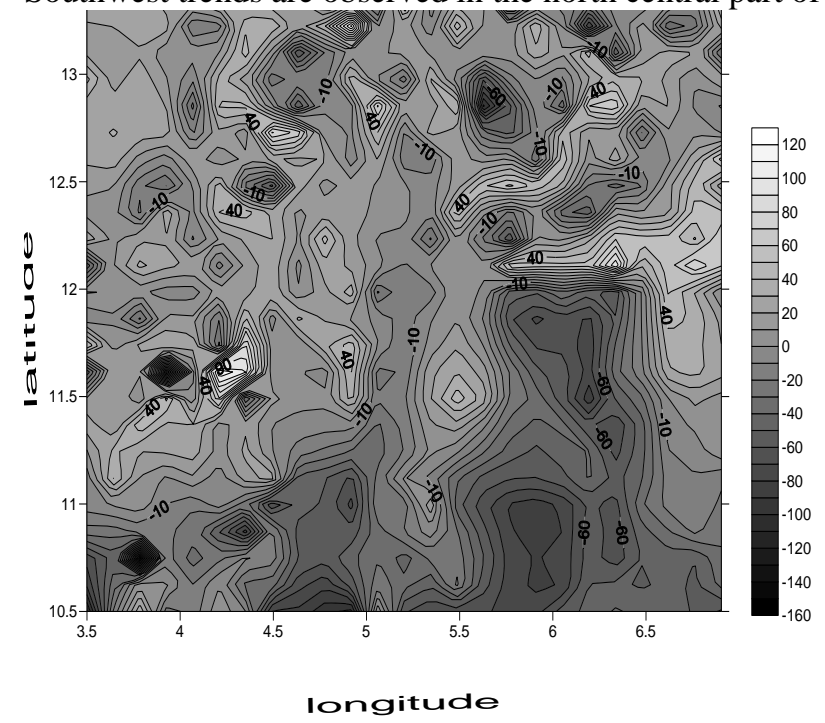

Figure 3Residual Magnetic Intensity Map of the study area. 


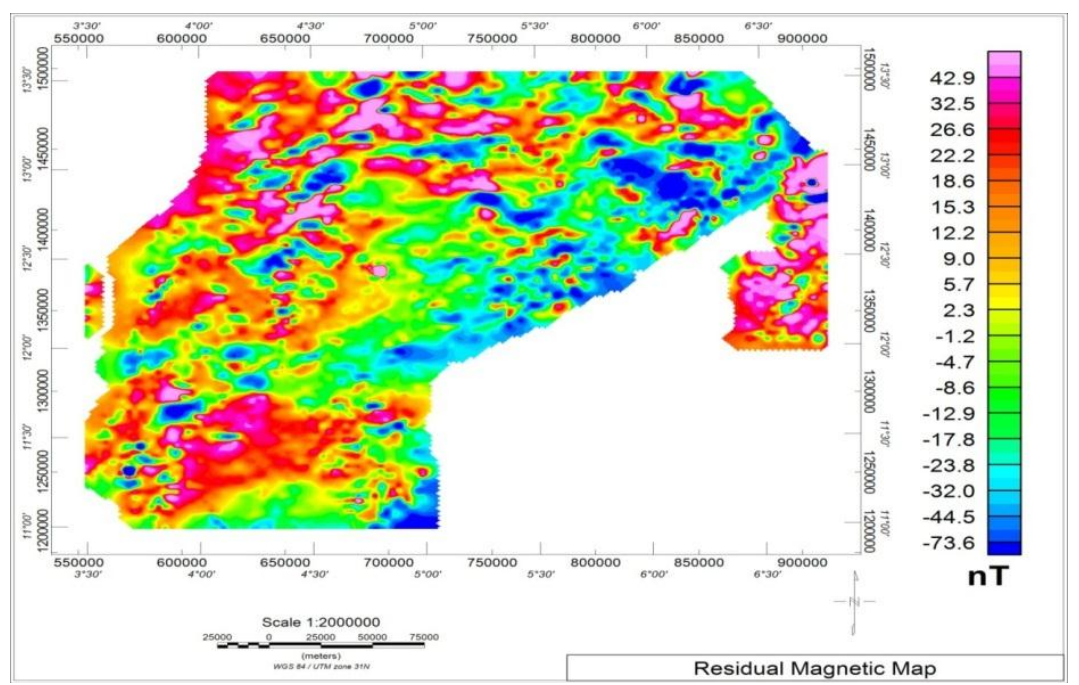

Figure 4 Residual Magnetic Intensity Map of the study area.

\subsection{Spectral Depth Analysis}

The results for the spectral depths estimates $\left(\mathbf{H}_{\mathbf{1}}\right.$ and $\left.\mathbf{H}_{\mathbf{2}}\right)$ are as tabulated (Table1) below.

The depth estimates obtained are superimposed on the total magnetic intensity map of the study area as shown in Figure 5

Table 1THE DEPTH ESTIMATES

\begin{tabular}{|c|c|c|c|}
\hline Section & Location & $\mathrm{H}_{1}(\mathbf{k m})$ & $\mathbf{H}_{2(\mathrm{KM}))}$ \\
\hline $\mathbf{1}$ & Sakkwabe & 0.04 & 1.82 \\
\hline 2 & Binji & 0.04 & 1.10 \\
\hline 3 & Sokoto & 0.07 & 2.50 \\
\hline 4 & Rabah & 0.04 & 1.67 \\
\hline 5 & Isah & 0.15 & 2.53 \\
\hline 6 & Kangiwa & 0.08 & 1.26 \\
\hline 7 & Lema & 0.05 & 1.75 \\
\hline 8 & Argungu & 0.27 & 2.74 \\
\hline 9 & Dange & 0.13 & 2.63 \\
\hline 10 & Gandi & 0.19 & 1.13 \\
\hline 11 & Mafara & 0.12 & 2.67 \\
\hline 12 & K/Namoda & 0.18 & 1.60 \\
\hline 13 & Zogirma & 0.50 & 1.42 \\
\hline 14 & B/Kebbi & 0.13 & 1.30 \\
\hline 15 & Tambuwal & 0.27 & 1.75 \\
\hline 16 & Gummi & 0.95 & 2.29 \\
\hline 17 & Ankah & 0.37 & 2.5 \\
\hline 18 & Maru & 0.12 & 2.40 \\
\hline 19 & Gusau & 0.28 & 2.0 \\
\hline 20 & Kamba & 0.11 & 2.46 \\
\hline 21 & Giru & 0.02 & 0.80 \\
\hline 22 & Fokku & 0.13 & 0.36 \\
\hline 23 & Danko & 0.17 & 0.42 \\
\hline 24 & Kaoje & 1.19 & 1.25 \\
\hline 25 & Shanga & 0.60 & 2.45 \\
\hline 26 & Zuru & 0.07 & 1.11 \\
\hline 27 & Konkosso & 0.08 & 1.52 \\
\hline 28 & Yelwa & 0.13 & 1.54 \\
\hline 29 & Chufu & 0.08 & 1.28 \\
\hline
\end{tabular}




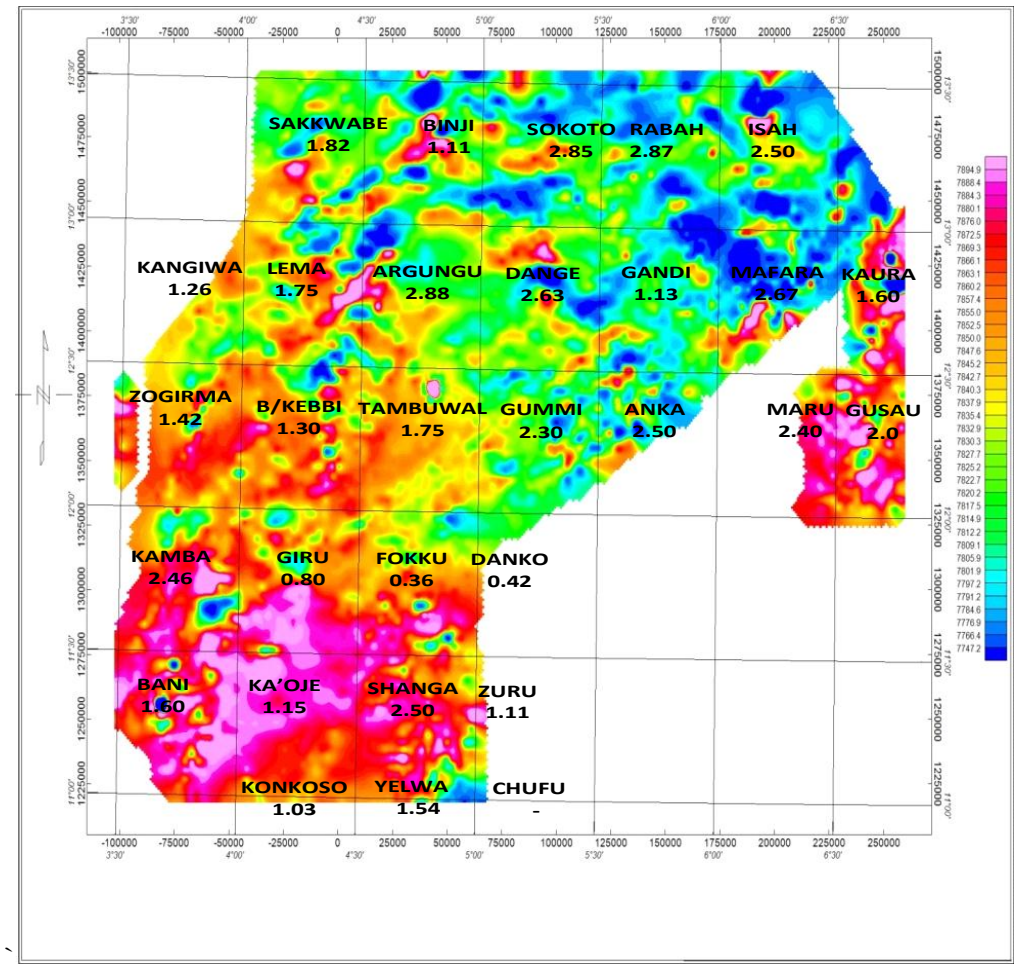

Figure 5 The Depth Estimates superimposed on TMI

\subsection{Contour of Basement Depth}

The contour of basement depth $\left(\mathrm{H}_{2}\right)$ of the study area is as shown in Figure 6

The depth contours depicts a number of basement depressions over the entire study area. The depth values suggest that the magnetic basement surface beneath the Sokoto sedimentary basin is generally shallow and of low relief. Depths to magnetic basement range from $0.36 \mathrm{~km}$ in the southern part to $2.85 \mathrm{~km}$ at the northwestern bordering with Niger republic. A closer observation indicates a general increase in thickness from the southern part to northern part, more especially the northwestern part bordering with Niger republic. This general trend in sedimentation implies that the Iullemmenden basin is thickest at the centre, which is at Niger republic.

The surface plot of the second layer $\left(\mathrm{H}_{2}\right)$ of the study area (Figure 6) shows similar trend with the total magnetic intensity map.

The surface shows the variation in depth of the magnetic source rocks. The peaks shows areas where sedimentation are relatively higher.

Two prominent sedimentary reservoirs are observed in north east and north central part of the map. The result agrees well with the results of the upward continuation at depths of $5 \mathrm{~km}$ and above.

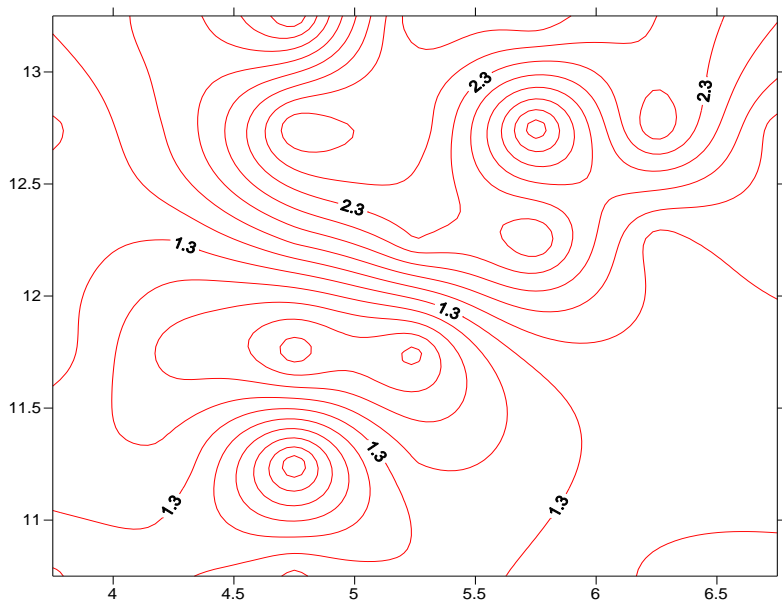

Figure 6The contour of basement depth $\left(\mathrm{H}_{2}\right)$ of the study area. 


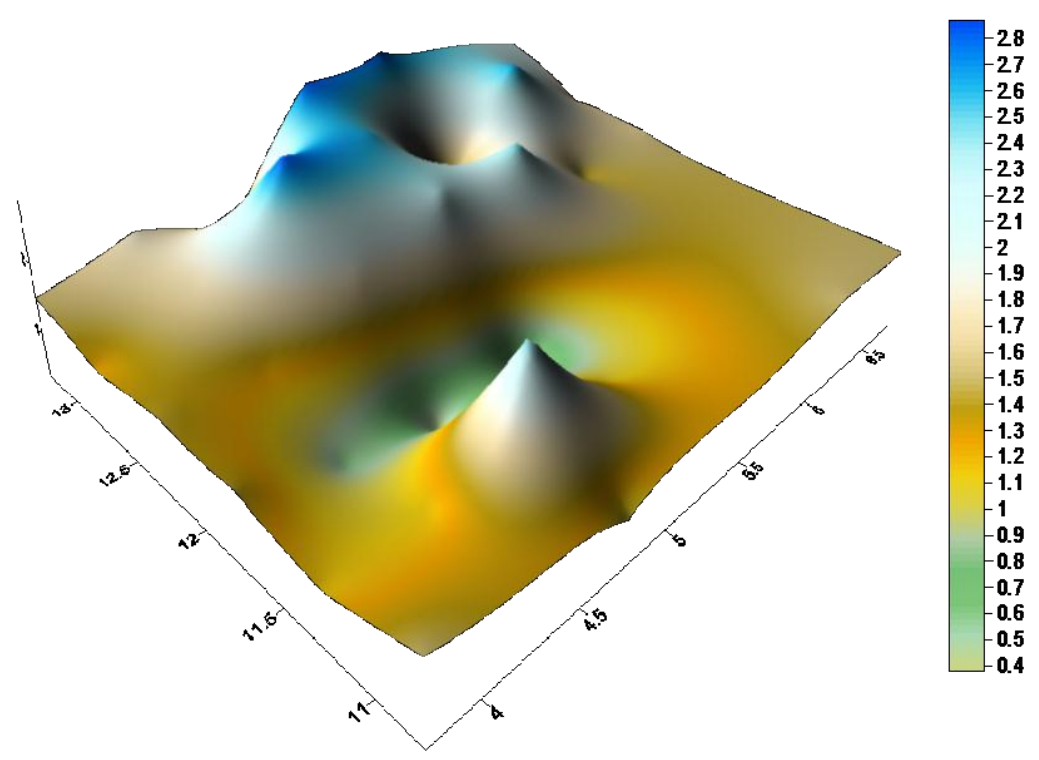

Figure 7 Contour of Surface Depth

\section{Conclusions}

The conclusion to be drawn from this work, based on the results of spectral depth analysis and modeling of the residual magnetic anomalies identified on the Total Magnetic Intensity (TMI) of Sokoto sedimentary Basin are as follow From this study, results obtained from the spectral depth analysis carried out sheet by sheet identified areas of Argungu (2.74km), Isah (2.50km), Mafara (2.67km), Ankah (2.50km) Gummi $(2.29 \mathrm{~km})$,Shanga $(2.84 \mathrm{~km})$ and Sokoto $(2.65 \mathrm{~km})$ having relatively higher sedimentation.

Results of the 2D Modeling carried out on the residual magnetic anomaly map encountered a maximum depth of $2.74 \mathrm{~km}$ in the vicinities of Argungu on profile 2.

Several depressions or variations in thickness have been observed in some parts of the Sokoto Basin, particularly around Argungu, ,Isah, Rabah and Gandi areas, These deeper sections of the Sokoto sedimentary basin identified in this study, might be probable potential sites for hydrocarbon deposits and is therefore recommended to be subjected to further investigation

Exploration of the Nigerian inland basins is worth given a push. Hydrocarbons if discovered and harnessed will increase the country's reserve and boost productivity. All these will have economic and strategic benefits for the country.

\section{References}

[1]. Corell, L. and Grouch, V.J.S. (1985), Mapping basement zones from magnetic data in the san juan basin; New Mexico: presented at the $52^{\text {nd }}$ Annual International Meeting, Society or exploration, geophysicists, Dallas U.S.A.

[2]. Dobrin, M.B. (1976), Introduction to Geophysical Prospecting. Mc-Graw Hill Books Co ( ${ }^{\text {rd }}$ Ed.) N.Y. Pp. 630

[3]. Hahn, A., Kind, E.G.and Mishra, D.C. (1976), Depth estimates of Magnetic sources by means of Fourier Amplitude Spectra. Geophy.Prosp 24,278- 308.

[4]. Kangkolo, D.E. Ojo, and S.B. (1976): The Influence of Outlier Points and their Suppression in theDetermination of Regional Fields by Polynomial Fitting. Proceedings of the $31^{\text {st }}$ Annual Conference of the Nigerian Mining and Geosciences Society.

[5]. Kearey, P, Brooks, M. and Hill, I. (2004), An Introduction to Geophysical Exploration. Third• Edition, Blackwell Pub.

[6]. Nigerian Geology Survey Agency,(1976), Geology Map of Nigeria. Scale1:2,00 000. Geology Survey of Nigeria, Kaduna, Nigeria

[7]. Oasis Montaj software inc.

[8]. Oppenheim,,A.V and Schafer R.W.(1975).Digital signal processing practice.Hall International Inc. New Jersey. Pp 1227-1296.

[9]. Reeves, C. ( 2005);Aeromagnetic Surveys; Principles, Practice and Interpretation, Training Programme, NGSA, Nigeria.

[10]. Reynolds, J.M. (1990): An introduction to applied and environmental Geophysics, John Willey and sons Limited Pp 116 - 207.

[11]. Surfer (R) version 8.012002 Golden software inc.

[12]. Spector, A. (1968),Spectral analysis of aeromagnetic data. Ph.D Thesis, University of Toronto, Canada.

[13]. Spector, A., and Grant, F.S. (1970), Statistical Models for interpreting aeromagnetic data. Geophysics Vol.(.35), Pp.293-302.

[14]. Udensi, E.E , sazuwa, J.B. and Daniyan, M.A. (2001), Production of a Composite Aeromagnetic Map of the Nupe Basin, Nigeria. Jour. of Sci. Tech.,aridMaths Educ.,Vol. 3(2) Pp $150-159$

[15]. Udensi.E.E.,Osazuwa, I-B. (2002), Two and Half Dimensional Modeling of the Major Structures Underlying the Nupe Basin, Nigeria using Aeromagnetic Data. Nigerian Journal of Physics (NJP).Vol. 14(1) Pp. 55 -61. 